\title{
Vibration Signal Processing-Based Detection of Short-Circuited Turns in Transformers: A Nonlinear Mode Decomposition Approach
}

\author{
Jose R. Huerta-Rosales ${ }^{1}$, David Granados-Lieberman ${ }^{2} \mathbb{B}$, Juan P. Amezquita-Sanchez ${ }^{1} \mathbb{(}$, \\ David Camarena-Martinez ${ }^{3}$ and Martin Valtierra-Rodriguez ${ }^{1, * \text { D }}$ \\ 1 ENAP-Research Group, CA-Sistemas Dinámicos, Facultad de Ingeniería, Universidad Autónoma de \\ Querétaro (UAQ), Campus San Juan del Río, Río Moctezuma 249, Col. San Cayetano, \\ San Juan del Río C. P. 76807, Mexico; roberto.huerta@enap-rg.org (J.R.H.-R.); \\ juan.amezquita@enap-rg.org (J.P.A.-S.) \\ 2 ENAP-Research Group, CA-Fuentes Alternas y Calidad de la Energía Eléctrica, Departamento de Ingeniería \\ Electromecánica, Tecnológico Nacional de México, Instituto Tecnológico Superior de Irapuato (ITESI), \\ Carr. Irapuato-Silao km 12.5, Colonia El Copal, Irapuato, Guanajuato C. P. 36821, Mexico; \\ david.granados@enap-rg.org \\ 3 ENAP-Research Group, CA Procesamiento Digital de Señales, Departamento de Electrónica, División de \\ Ingenierías Campus Irapuato-Salamanca (DICIS), Salamanca, Guanajuato C. P. 36885, Mexico; \\ david.camarena@enap-rg.org \\ * Correspondence: martin.valtierra@enap-rg.org
}

Received: 23 March 2020; Accepted: 10 April 2020; Published: 13 April 2020

\begin{abstract}
Transformers are vital and indispensable elements in electrical systems, and therefore, their correct operation is fundamental; despite being robust electrical machines, they are susceptible to present different types of faults during their service life. Although there are different faults, the fault of short-circuited turns (SCTs) has attracted the interest of many researchers around the world since the windings in a transformer are one of the most vulnerable parts. In this regard, several works in literature have analyzed the vibration signals that generate a transformer as a source of information to carry out fault diagnosis; however this analysis is not an easy task since the information associated with the fault is embedded in high level noise. This problem becomes more difficult when low levels of fault severity are considered. In this work, as the main contribution, the nonlinear mode decomposition (NMD) method is investigated as a potential signal processing technique to extract features from vibration signals, and thus, detect SCTs in transformers, even in early stages, i.e., low levels of fault severity. Also, the instantaneous root mean square (RMS) value computed using the Hilbert transform is proposed as a fault indicator, demonstrating to be sensitive to fault severity. Finally, a fuzzy logic system is developed for automatic fault diagnosis. To test the proposal, a modified transformer representing diverse levels of SCTs is used. These levels consist of 0 (healthy condition), 5, 10, 15, 20, and 25 SCTs. Results demonstrate the capability of the proposal to extract features from vibration signals and perform automatic fault diagnosis.
\end{abstract}

Keywords: fault diagnosis; fuzzy logic; nonlinear mode decomposition; short-circuit fault; transformers; vibration signals

\section{Introduction}

Transformers represent one of the most expensive and significant elements of a power network [1]. Therefore, their correct operation is fundamental for both utilities and consumers. In general, they are robust and reliable machines; however, because of inherent operating conditions, they are subject 
to different power quality problems and harsh operating conditions that can lead to different faults such as winding and core deformations, broken clamping structures, and short-circuited turns, among others [2,3]. Among these faults, winding faults have attracted the interest of many researchers around the world since they represent around $30 \%-50 \%$ of the total faults in a transformer [4].

To perform fault diagnosis in transformers, different methods have been proposed, e.g., dissolved gas analysis, power factor testing, thermography, frequency response analysis, insulating oil quality, energization current, and vibration analysis, among others [5-8]. Although promising results have been obtained, some issues still remain unsolved in several diagnostic methods. For instance, the analysis of energization currents requires further research in order to properly differentiate between an energization current and a short-circuit fault current; on the other hand, temperature measurement-based diagnosis methods require long observation times. In recent years, vibration analysis has demonstrated, on one hand, to overcome some drawbacks of the aforementioned methods [5] and, on the other hand, to improve the diagnosis results through its combination with other methods [9], becoming a very attractive topic for many researchers around the world. Another advantage is that the vibration signals maintain a direct relation with the mechanical performance of the winding $[4,5,10]$; from this point of view, changes or alterations in the windings will modify the vibration patterns. In this regard, the diagnosis task relies on extracting and characterizing such patterns; yet, it is not an easy task since the vibration signals have nonstationary and nonlinear properties and are embedded in high level noise, compromising the performance of many signal processing techniques. Furthermore, the problem becomes more difficult when faults of low severity are considered.

In this work, a new methodology to diagnose short-circuit faults in transformers is presented. As the main contribution, the nonlinear mode decomposition (NMD) method is investigated as potential signal processing technique to detect short-circuited turns (SCTs) in transformers from vibration signals, which to the best of authors' knowledge, has not been reported yet, mainly on early fault stages. Furthermore, the root mean square (RMS) index computed from the Hilbert transform is proposed as fault severity indicator and a fuzzy logic (FL) system is developed to perform automatic diagnosis. To test the proposal in a real scenario, a transformer adapted with different fault severity levels, ranging from 0 to 25 SCTs with steps of 5 turns, where 0 turns represent the healthy condition, is used. Results demonstrate the effectiveness and usefulness of the proposal to assess the transformer condition as the proposal can detect different fault severities in an automatic way.

\section{Related Literature}

In the literature, the diagnosis techniques for vibration analysis can be separated in signal processing-based and model-based techniques [11]. Model-based techniques implement relations between the measured vibration signal and certain input parameters to assess the transformer condition through the comparison of a reference value and the measured value. For instance, Garcia et al. in $[12,13]$ propose a model based on the tank vibration of a transformer using the fundamental frequency component to determine winding deformations. Hong et al. [1] acquire signals from several sensors and perform a vibration correlation analysis in order to propose a model and assess the winding condition. A model coupled with and electromagnetic force analysis to detect winding faults is also presented by Zhou et al. [14]. On the other hand, the signal processing-based techniques extract features directly from vibration signals in order to perform a fault detection. The most common technique to extract frequency information is the Fourier transform (FT) $[10,15,16]$. Bartoletti et al. [10] propose a set of parameters based on the FT to diagnose the transformer. Two metrics, the root mean square (RMS) and the RMS deviation, both obtained from the FT are used to detect mechanical faults in power transformers [15]. Hong et al. [16] introduce the frequency complexity analysis using entropy as a measure of frequency uncertainty. Although promising results have been presented, the performance of FT can be compromised when the analyzed signal presents nonstationary events. For these types of events, a variant of the FT called short-time FT (STFT) is preferred. This method offers the evolution overtime of nonstationary properties of a signal. The STFT is used by Borucki [17] to identify differences 
between diverse conditions of a transformer under transient operating conditions. In general, STFT is a powerful and low-complex tool for the analysis of nonstationary signals; yet, a compromise between frequency resolution and time resolution has to be properly established, which is not an easy task for signals with unknow properties. Another technique for the analysis of nonstationary signals is the Wavelet transform (WT), which decomposes a nonstationary signal in a set of frequency bands overtime. In [18-20], the WT is used to decompose vibrations signals, and thus, extract features that allow the fault detection in transformers. Some variations of the WT, i.e., wavelet package transform [21] and empirical wavelet transform [22], are also reported to extract features and diagnose different fault conditions in transformers. It is worth noting that the success of the WT-based methods depends on the proper selection of the mother wavelet and decomposition level [23], which change for different applications. In this regard, adaptive techniques become attractive solutions, where the empirical mode decomposition (EMD)-based methods have been the most widely used [24-28]. In [25], the EMD is used to process vibration signals in a transformer under DC bias. A comparison of three EMD-based methods to detect SCTs in transformers is presented in [26]. In [27,28], an improved version of the EMD is presented for fault diagnosis and modal parameter estimation, respectively. The EMD-based analysis for vibrations signals in other fields has been also reported in literature [29-32]. Despite the adaptive advantages of the EMD-based methods, some issues such as mode mixing, noise, and the lack of physical meaning for the decomposed modes can compromise their effectiveness [33]. A recent technique developed by Iatsenko et al. [33], the nonlinear mode decomposition (NMD), solves the drawbacks previously mentioned since it decomposes a complex waveform signal into a set of modes with physical meaning and, simultaneously, removes noise, making it a potential solution to analyze noisy vibrations signals with nonlinear and nonstationary properties as the ones presented in transformers.

\section{Theoretical Background}

This section provides the theoretical background for the topics employed in this research.

\subsection{Transformer Vibrations}

Transformer vibrations are generated principally by the forces that appear in the core and the winding during the transformer operation [34]. The forces into the core are produced by the magnetostriction phenomenon. This phenomenon occurs on ferromagnetic materials when they are subject to a magnetic field [11]. In this regard, the applied voltage and its relation with the magnetic induction makes the magnetostriction forces $\left(F_{\text {core }}\right)$ proportional to the voltage $(V)$ squared as follows [34]:

$$
F_{\text {core }} \propto V^{2}
$$

On the other hand, the winding vibrations are generated by the electrodynamic forces that occur in the windings because of the interaction of the consumed current and the magnetic leakage flux [34]. Similar to Equation (1), these forces $\left(F_{\text {winding }}\right)$ are proportional to the current $(I)$ squared as follows:

$$
F_{\text {winding }} \propto I^{2}
$$

It is worth noting that the magnetostriction is a nonlinear phenomenon that induces harmonic components into the vibration signal [11]; also, some harmonic components appear because of the magnetizing current or some residual currents [34], which affects negatively the vibration analysis.

\subsection{Nonlinear Mode Decomposition (NMD) Method}

Complex systems as transformers generate signals composed of different oscillation modes, including the unavoidable background noise [33]; for a correct analysis of these signals, these modes should be correctly separated from each other. The NMD method is presented as an adaptive decomposition tool for nonlinear and nonstationary signals, which decomposes a given signal into 
a set of modes with physical meaning modes, and at the same time, removes the background noise. This method is based on the following steps [33,35-37]:

- Preprocessing. To obtain a suitable time frequency representation (TFR), a preprocessing of the input signal can be carried out. An essential step is to eliminate trends using a third order polynomial and extracting the bandwidth of interest by means of a bandpass filter.

- Time-Frequency Representation (TFR). A TFR allows simultaneously studying the properties, i.e., amplitude, frequency, and phase, from a signal in both time domain and frequency domain. The NMD uses the STFT, i.e., the Fourier transform of a windowed input signal. It is typically constructed as:

$$
G(\omega, t)=\int s^{+}(u) g(u-t) e^{-i \omega(u-t)} d u=e^{-i \omega t} \frac{1}{2 \pi} \int_{0}^{\infty} e^{-i \xi t} \hat{s}(\xi) \hat{g}(\omega-\xi) d \xi
$$

where $s^{+}(u)$ represents the use of positive frequencies, $g(u)$ is a specific window function (positive part) and $\hat{g}(\xi)$ its FT. The window used is the Gaussian window given by:

$$
g(u)=\frac{B_{f_{0}}}{f_{0} \sqrt{2 \pi}} e^{-u^{2} / 2 f_{0}^{2}} \Leftrightarrow \hat{g}(\xi)=B_{f_{0}} e^{-f_{0}^{2} \xi / 2}
$$

where $f_{0}$ is the resolution parameter which controls the spread of a Gaussian window in time and frequency, i.e., it controls the time and frequency resolution that are inversely proportional to each other, and $B_{f 0}$ is a normalization factor. The window parameters and their selection are discussed in [36].

- Component extraction and reconstruction. The following step is carried out to obtain the component with the highest energy, i.e., the fundamental component, from the TFR. To extract components from a TFR, it is necessary to find its ridge curve as:

$$
S\left[\omega_{p}(t)\right]=\sum_{n=1}^{N}\left[\log \left|G_{s}\left(\omega_{p}\left(t_{n}\right), t_{n}\right)\right|-\frac{1}{2}\left(\frac{\left|\Delta \omega_{p}\left(t_{n}\right)-\left\langle\Delta \omega_{p}\right\rangle\right|}{s t d\left[\Delta \omega_{p}\right]}\right)^{2}-\frac{1}{2}\left(\frac{\omega_{p}\left(t_{n}\right)-\left\langle\omega_{p}\right\rangle}{s t d\left[\omega_{p}\right]}\right)^{2}\right]
$$

where $\omega_{p}(t)$ is a ridge point, which is an exclusive sequence for the TFR amplitude peaks, $\Delta \omega_{p}$ is equal to $\omega_{p}\left(t_{n}\right)-\omega_{p}\left(t_{n-1}\right),<f(t)>$ is the mean value of $f(t)$, and $s t d[f(t)]$ represents the standard deviation of $f(t)$. From the ridge curve, the instantaneous amplitude $A(t)$, phase $\phi(t)$, and frequency $v(t)$ can be reconstructed using two different methods: ridge method and direct method. The former is given by:

$$
v(t)=\omega_{p}(t)+\delta v_{d}(t), A(t) e^{i \phi(t)}=\frac{2 G_{s}\left(\omega_{p}(t), t\right)}{\hat{g}\left(\omega_{p}(t)-v(t)\right)}
$$

where $\delta v_{d}(t)$ is a correction for the discretization effects through a quadratic interpolation. On the other hand, the direct method uses a region in the TFR called time-frequency support $\left[\omega_{-}(t), \omega_{+}(t)\right]$. The parameters can be reconstructed as:

$$
\begin{aligned}
& A(t) e^{i \phi(t)}=C_{g}^{-1} \int_{\omega_{-}(t)}^{\omega+(t)} G_{S}(\omega, t) d \omega, C_{g} \equiv \frac{1}{2} \int_{-\infty-}^{\infty} \hat{g}(\xi) d \xi=\pi g(0), \\
& v(t)=\operatorname{Re}\left[\frac{\int_{\omega_{-}(t)}^{\omega_{+}(t)} \omega G_{s}(\omega, t) d \omega}{\int_{\omega_{-}(t)}^{\omega_{(}(t)} G_{s}(\omega, t) d \omega}\right]
\end{aligned}
$$

The choice between the two methods depends on the amount of noise and the amplitude/frequency variation of the component to be extracted. The criteria used for an adaptive choice are shown in [36].

- Test the parameters against noise. After extraction of each NM, the extracted parameters must be tested against noise to decide if the decomposition continues or not, i.e., if the residual signal is 
composed by noise then the decomposition ends. To do so, the surrogate test is used. This test takes the inverse FT of the resulting FT of the in-test signal but with random phases. The discriminant statistics, $D$, for the surrogate test are calculated as a combination of the spectral entropies, $Q$, of the values obtained for amplitude and frequency as follows:

$$
D\left(\alpha_{A}, \alpha_{f}\right)=\alpha_{A} Q[\hat{A}(\omega)]+\alpha_{f} Q[\hat{f}(\omega)]
$$

where $Q|f(x)|$ is the spectral entropy and is defined as follows:

$$
Q[f(x)]=-\int \frac{|f(x)|^{2}}{\int|f(x)|^{2} d x} \ln \frac{|f(x)|^{2}}{\int|f(x)|^{2} d x}
$$

In [32], it is recommended to carry out three tests and select the maximum value. These tests use $D(1,0), D(0,1)$, and $D(1,1)$. If the null hypothesis is rejected for one of them, the component is not noise and the decomposition has to continue.

- Extraction of harmonics. The component extracted and identified as genuine will represent a harmonic of some NM. Assuming that the extracted harmonic is the fundamental component with instantaneous frequency $v^{(1)}(t)$, then the harmonics $h=2,3, \ldots N$ and their instantaneous frequencies $h v^{(1)}(t)$ can be also obtained; hence, the ridge curve $\omega_{p}^{h}(t)$ from the $h$ harmonic can be extracted. $N$ is set according to the Nyquist theorem. Nevertheless, if the assumption is not correct, it is necessary to find the fundamental component by applying the same procedure but in inverse direction, i.e., using $h=1 / 2,1 / 3, \ldots$. To identify a harmonic component as genuine, the method of surrogate data is used [33]. The following parameters are used to quantify the consistency degree between two harmonics, i.e., the first extracted harmonic and the last extracted harmonic, using amplitude, phase, and frequency information.

$$
\begin{aligned}
q_{A}^{h} & \equiv \exp \left[-\frac{\sqrt{\left\langle\left[A^{h}(t)\left\langle A^{1}(t)\right\rangle-A^{1}(t)\left\langle A^{h}(t)\right\rangle\right]^{2}\right\rangle}}{A^{1}(t) A^{h}(t)}\right] \\
q_{\phi}^{h} & \equiv\left|\left\langle\exp \left[i\left(\phi^{h}(t)-h \phi^{1}(t)\right)\right]\right\rangle\right| \\
q_{v}^{h} & \equiv \exp \left[-\frac{\sqrt{\left\langle\left[v^{h}(t)-h v^{1}(t)\right]^{2}\right\rangle}}{\left\langle v^{h}(t)\right\rangle}\right]
\end{aligned}
$$

A general measure of interdependence between harmonics is constructed by:

$$
\rho^{h}\left(w_{A}, w_{\phi}, w_{v}\right)=\left(q_{A}^{h}\right)^{w_{A}}\left(q_{\phi}^{h}\right)^{w_{\phi}}\left(q_{v}^{h}\right)^{w_{v}}
$$

where $w_{A, \phi, v}$ represents the weights to each value of consistency $q_{A, \phi, v}^{h}$. The $\rho^{h}(1,1,0)$ can be used by default [33].

- $\quad$ Reconstruct the NM. After extracting all the genuine harmonics, the full NM can be constructed. In addition, it is expected that components with higher amplitudes have less noise; nevertheless, the harmonic parameters of each component are refined through a weighted average over all the harmonic parameters as follows: 


$$
\begin{aligned}
& \widetilde{A}^{(h)}(t)=\left\langle A^{(h)}(t)\right\rangle \frac{\sum h^{\prime} A^{\left(h^{\prime}\right)}(t)}{\sum h^{\prime}\left\langle A^{\left(h^{\prime}\right)}(t)\right\rangle} \\
& \widetilde{\phi}^{(h)}(t)= \arg \left(\sum_{h^{\prime}} \min \left(1, \frac{h^{\prime}}{h}\right)\left\langle A^{\left(h^{\prime}\right)}(t)\right\rangle \exp \left[j \frac{h \phi^{\left(h^{\prime}\right)}(t)-\Delta \phi_{h^{\prime}, h}}{h^{\prime}}\right]\right. \\
&\left.\times \exp \left\{-j \frac{2 \pi}{h^{\prime}} \operatorname{round}\left[\frac{h \phi^{\left(h^{\prime}\right)}(t)-h^{\prime} \phi^{(h)}-\Delta \phi_{h^{\prime}, h}}{2 \pi}\right]\right\}\right) \\
& \widetilde{v}^{(h)}(t)=\frac{\sum h^{\prime} \min \left(1, \frac{h^{\prime}}{h}\right) A^{\left(h^{\prime}\right)}(t) h v^{\left(h^{\prime}\right)} / h^{\prime}}{\sum h^{\prime} \min \left(1, \frac{h^{\prime}}{h}\right)\left\langle A^{\left(h^{\prime}\right)}(t)\right\rangle}
\end{aligned}
$$

where $\Delta \phi_{h^{\prime}, h}=\arg \left(\exp \left\{j\left[h \phi^{\left(h^{\prime}\right)}(t)-h^{\prime} \phi^{(h)}(t)\right]\right\}\right)$.

- Finally, subtract the NM of the signal. The found NM must be extracted from the input signal before repeating the process to extract the next NM from the residual signal. Further information about the overall NMD method can be found in [33,35-37].

\subsection{Hilbert Transform}

For decomposition methods, further processing is required in many cases in order to extract and quantify different features or patterns. The Hilbert Transform (HT) is a lineal operation employed to compute instantaneous amplitude, phase, and frequency of a time series signal. In general, HT converts an input signal $x(t)$ into a signal $y(t)$ applying a convolution between $x(t)$ and the impulse response $h(t)=1 / \pi t$, which is defined as [38]:

$$
y(t)=H[x(t)]=\frac{1}{\pi} P \int \frac{x\left(t^{\prime}\right)}{t-t^{\prime}} d t^{\prime}
$$

where $P$ denotes the Cauchy principal value. Thus, $x(t)$ and $y(t)$ form a complex conjugate pair, also called analytic signal [39], given by:

$$
z(t)=x(t)+y(t)=A(t) e^{i \phi(t)}
$$

where $A(t)=\left[x^{2}(t)+y^{2}(t)\right]^{1 / 2}$ is the amplitude, $\phi(t)=\arctan [y(t) / x(t)]$ is the phase, and $v(t)=$ $d \phi(t) / d t$ is the frequency. From the amplitude or envelope of a signal, the RMS index can be computed using:

$$
\operatorname{RMS}(t)=A(t) / \sqrt{2}
$$

When a signal presents unwanted variations overtime, a moving average filter (MAF) can be used to smooth or cancel out such variations. This type of filter is implemented as a finite-impulse-response (FIR) filter by using Equation (15) [40]. The window length has $N$ samples and defines the filter order, while $x$ is the signal input. In the filter, the present sample, $n$, and the previous sample, $k$, are considered.

$$
y(n)=\frac{1}{N} \sum_{k=1}^{N} x(n-k)
$$

\subsection{Fuzzy Logic Systems}

Among different classification algorithms, FL systems can be designed from a priori knowledge [41], i.e., when some features about the input data are known. In general, this knowledge is established through a set of if-then-else classification rules. To implement an FL system, four steps are required [41, 42]: (i) fuzzification to convert the inputs into information that can be recognized by the inference mechanism, (ii) inference mechanism to process the information and take the decisions, (iii) rule-based structure to assign the inputs to a specific class using the stated set of rules, and (iv) defuzzification to map the inference mechanism conclusion into data that the user can understand. In the fuzzification, different membership functions such as Gaussian, triangular, trapezoidal, and other shapes can be used. 


\section{Methodology}

The proposed methodology to analyze vibration signals and detect SCT faults is shown in Figure 1. Firstly, a single-phase transformer with no load is used to obtain vibration signals under different conditions. The transformer used has been modified to simulate in a controlled way different conditions of fault. These conditions are: 0 (healthy), 5, 10, 15, 20, and 25 SCTs. The energization of the transformer is through a solid-state relay and the transformer is always operating at rated conditions. Then, the vibration signals for the three axes $\left(A_{x}, A_{y}, A_{z}\right)$ are acquired. These signals contain both transient state and steady state due to the energization current.

After the acquisition and by considering that the acquired vibration signals have nonstationary and nonlinear properties, the NMD method is used to extract their nonlinear modes. Once the modes have been extracted, the HT is used to compute the instantaneous amplitude of each mode. With this value and inspired from other works, the RMS index is computed in order to provide a fault indicator according to its severity. Due to the inherent nature of the vibration signals, some variations in the RMS values are expected overtime; in order to smooth and allow a better discrimination between different transformer conditions, an MAF is applied. Finally, an FL system is proposed to automatically determine the fault condition.

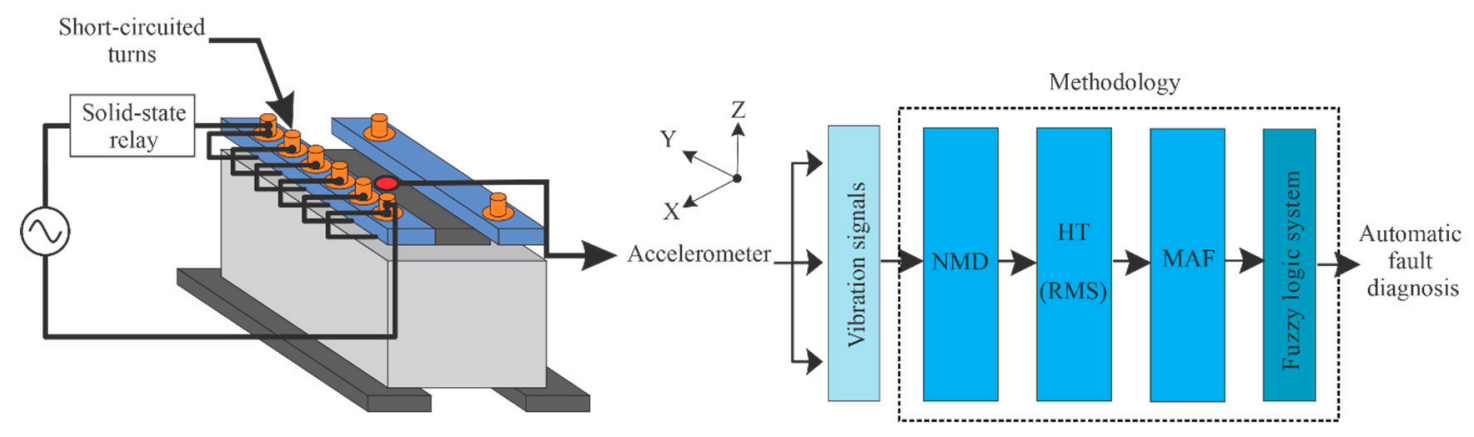

Figure 1. Flowchart for the proposed methodology.

\section{Experimentation and Results}

\subsection{Experimental Setup}

To test and validate the proposed methodology, the experimental setup shown in Figure 2 is used. The single-phase transformer used is a $1.5 \mathrm{kVA}$ with 135 turns in its primary winding and is operated at $120 \mathrm{~V}$. This transformer is modified to simulate different severities of fault in a controlled way, i.e., $0,5,10,15,20$, and 25 SCTs. A 3-axial accelerometer is used to measure the vibration from the transformer. It is an 8395A model from KISTLER, measuring $\pm 10 \mathrm{~g}$ with a resolution of $400 \mathrm{mV} / \mathrm{g}$ over a bandwidth of $1000 \mathrm{~Hz}$. To perform the acquisition of vibration signals, the accelerometer is located at the center of the core in order to receive the core and winding vibrations in a symmetrical way, and a data acquisition system (DAS) using a 16-bit analog-to-digital converter with a sampling frequency of 6000 samples/s is configured. This sampling frequency satisfies the Nyquist theorem for the accelerometer bandwidth. The DAS is based on the NI-USB 6211 board from National Instruments. Two solid-state relays, SAP4050D models, are used. The first one is used to activate the transformer and start the test, and the second one is used to activate an autotransformer and de-energize the transformer after each test, cancelling out the remnant flux. For statistical purposes, 20 tests for each condition are performed, where the acquisition time in each test is 5 s, i.e., 30,000 samples. All the vibration signal processing is carried out in a personal computer (PC) using the Matlab software. 


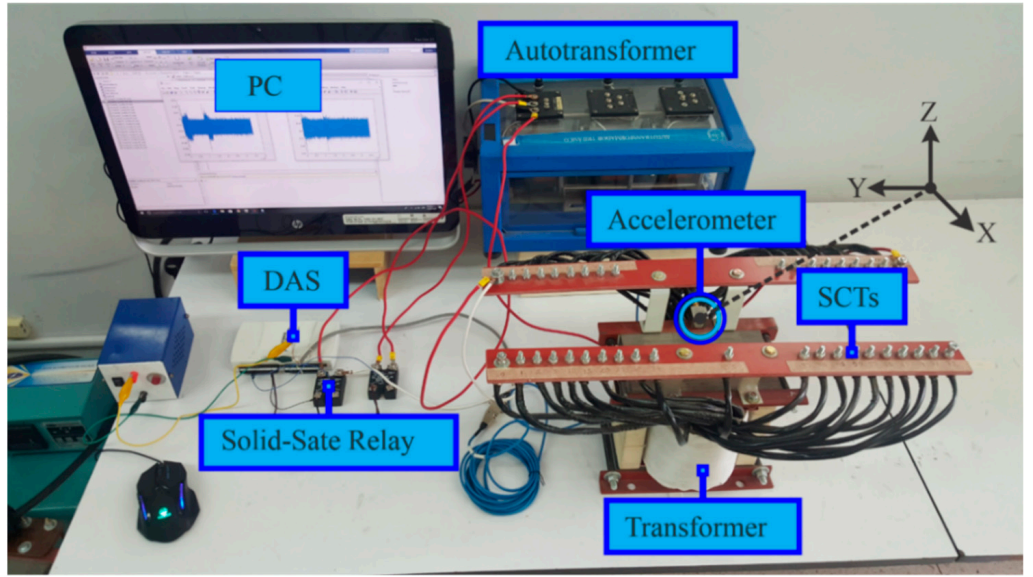

Figure 2. Experimental setup.

\subsection{Results}

The vibration signals, $A_{x}, A_{y}, A_{z}$, for 0 and 25 SCTs are shown in Figure 3a. For space reasons, these two extreme conditions are only shown. As can be observed, the transient state is shorter for a fault condition. It is worth noting that the transient state in the vibration signals is due to the energization current as shown in Figure 4.

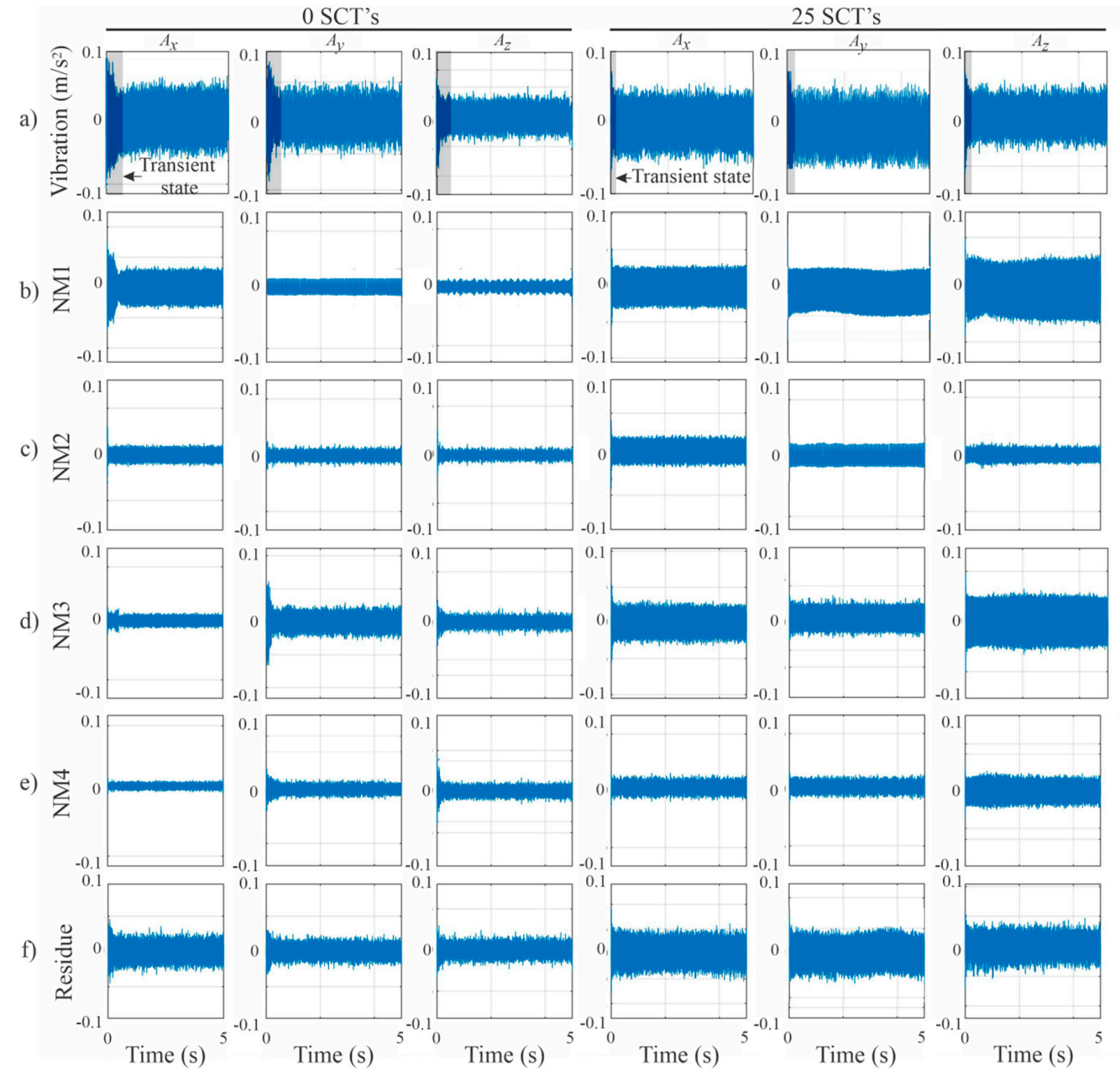

Figure 3. (a) Vibration signals, (b) nonlinear mode 1 (NM1), (c) nonlinear mode 2 (NM2), (d) nonlinear mode 3 (NM3), (e) nonlinear mode 4 (NM4), (f) Residues. 


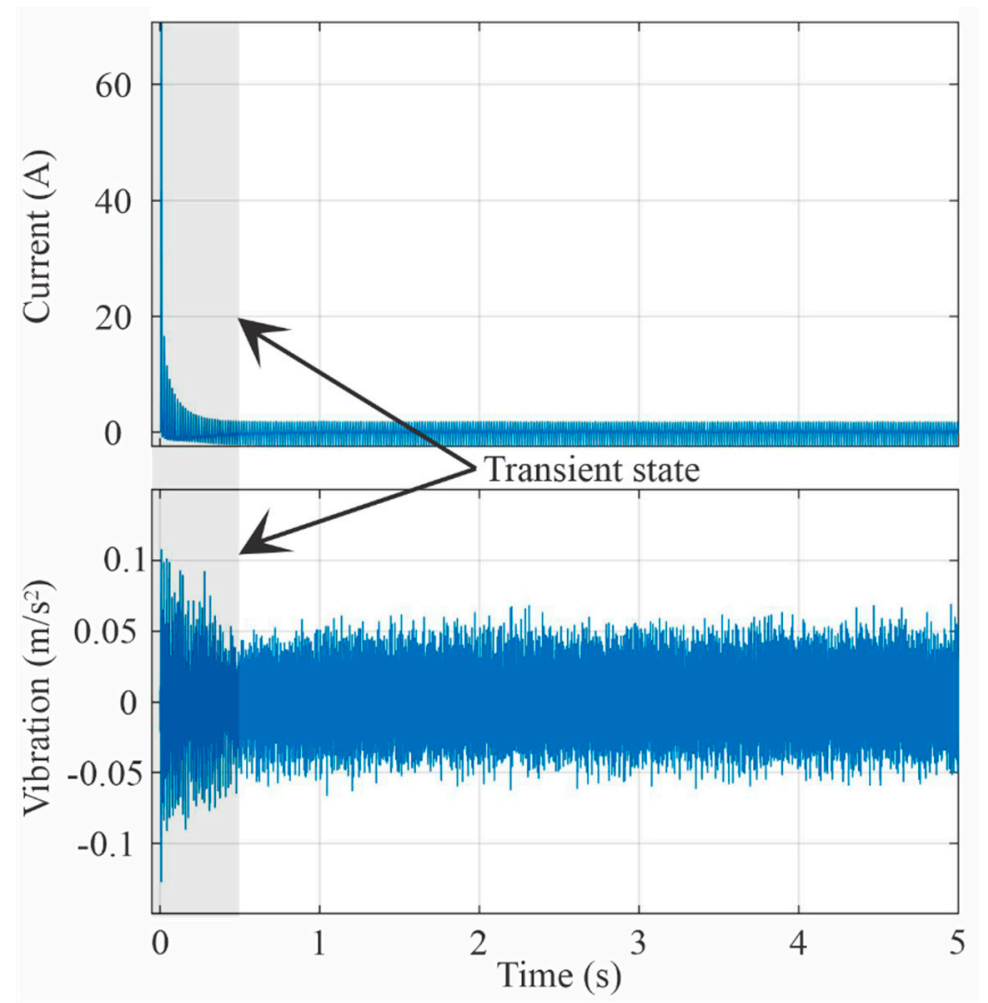

Figure 4. Current and vibration signals.

These transient states and the noise contained in the vibration signals generate negative effects in conventional signal processing techniques. Figure 5 shows the FT-based spectra obtained for two SCT conditions, where it can be observed that there are different changes (denoted by dotted red circles) in the frequency content; however, these components are not reliable due to the inherent drawbacks of FT to analyze nonstationary signals; in fact, these components change from test to test due to the noise, leakage effect, and transient conditions.

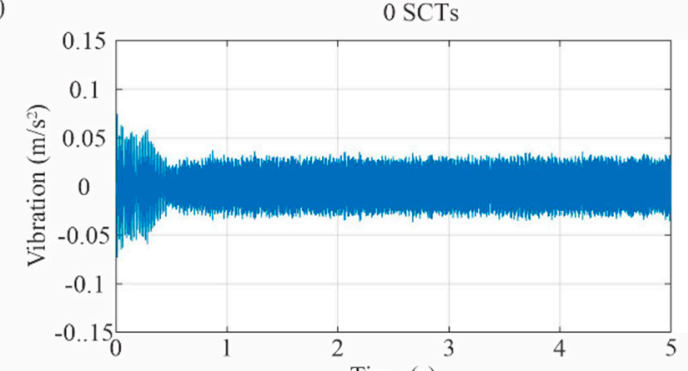

b)

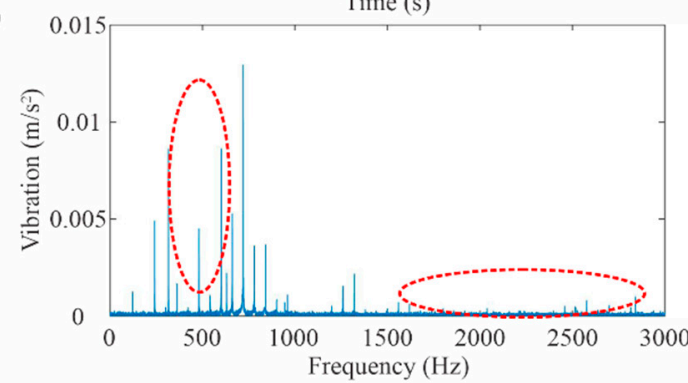

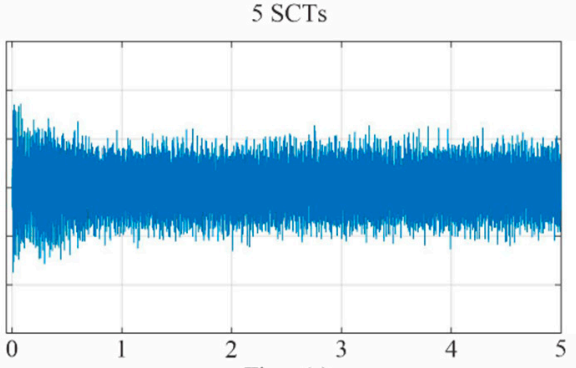

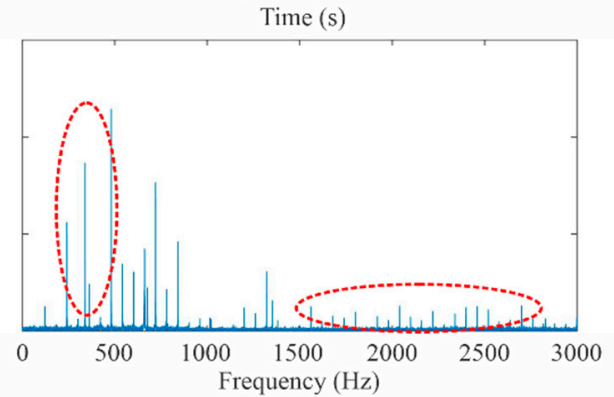

Figure 5. Vibration signals in (a) time domain and (b) frequency domain.

For the signals shown in Figure 3a, the NMD is then applied. Figure $3 b-f$ show the obtained results, i.e., four modes and their residue. From all these plots, it is possible to observe an amplitude 
level difference between conditions, which can be useful to identify the severity of the fault. In this regard, the HT is applied to each NM to obtain amplitude-related parameters, i.e., the RMS index. Figure 6 shows the RMS results using Equation (15). In order to reduce the number of analyzed modes, the most useful modes must be selected. From a visual inspection, the NM1 for Ay (plots shaded in gray) shows the maximum separation between conditions; therefore, it is selected to carry out the classification task by including other fault severities.

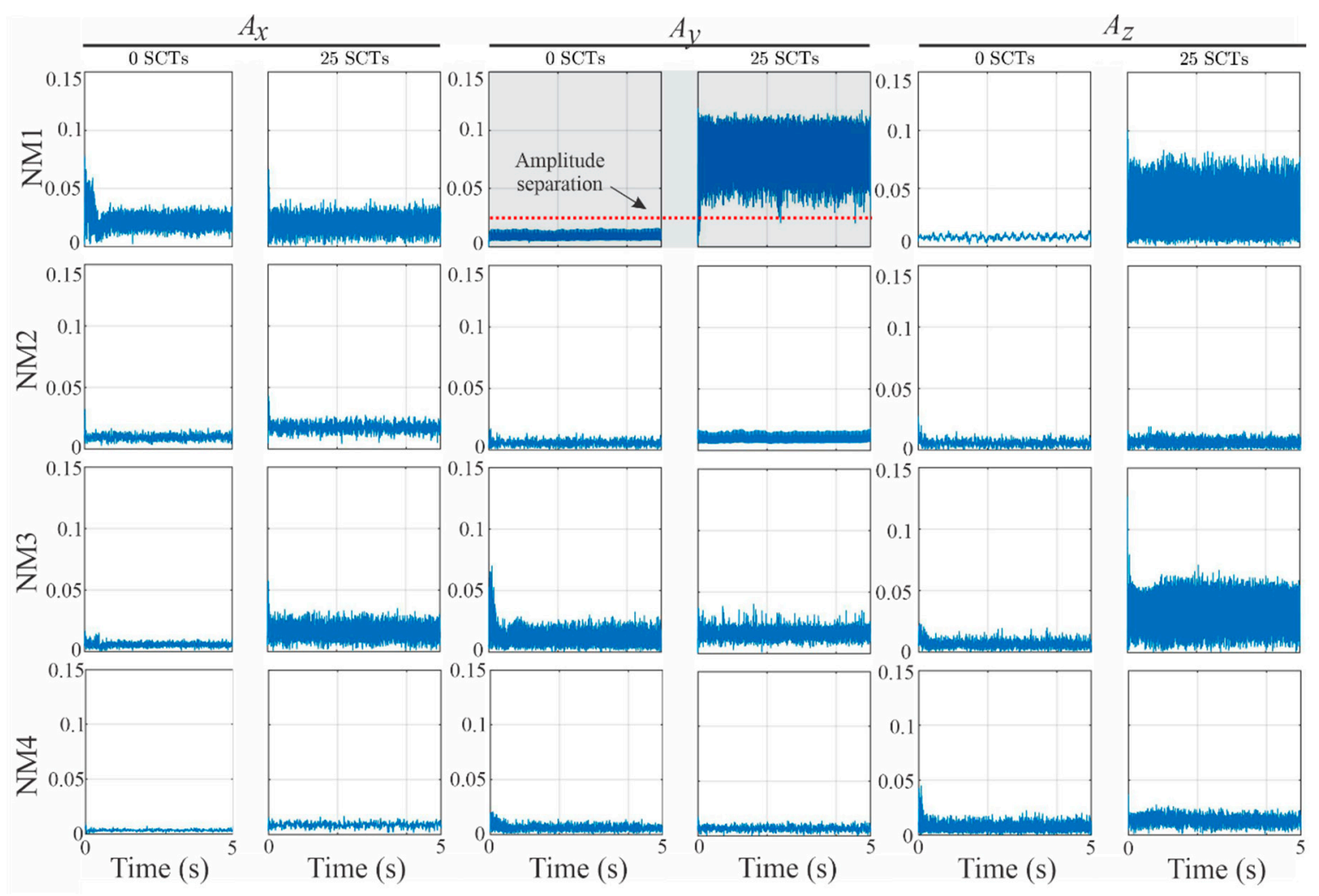

Figure 6. Root mean square (RMS) values for the NMs.

In order to improve the amplitude separation by smoothing the unwanted variations, an MAF with an order of 100 is applied. The order is selected by means of a trade-off between the converge time and the signal smoothness; at this stage, the frequency content is not that important since the NMD has been already applied. The obtained results for the selected mode, i.e., NM1 in $A y$, are shown in Figure 7; as can be observed, the amplitude separation is higher and has a smoother behavior. This improvement is also observed in other modes of Figure 6. After an exhaustive analysis, it is found that the best results are obtained in two modes: NM4 in $A x$ and NM1 in $A y$. Figure 8 shows the results for all the SCT fault conditions; in general, a proportional trend due to the fault severity is observed, indicating that the RMS index is sensitive to the fault severity in both transient and steady states, which is possible because the NMD method can deal with nonstationary signals. In particular, the proportional trend for 20 SCTs and 15 SCTs conditions in the NM4 for Ax does not continue; yet, the existing separation allows their correct identification. 


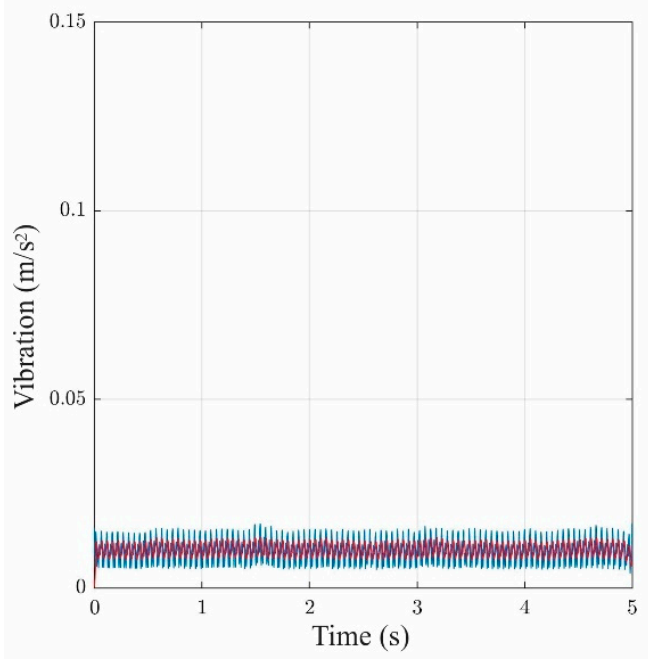

a)

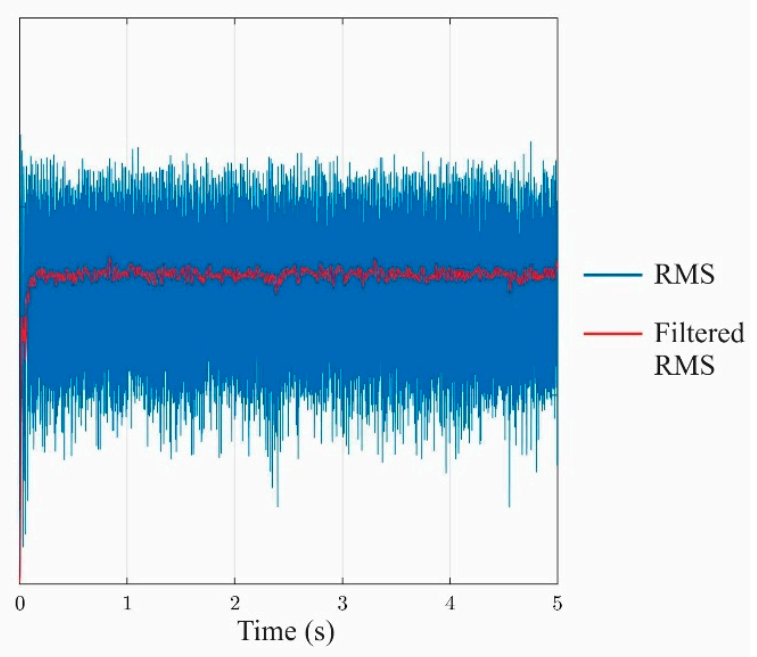

b)

Figure 7. Instantaneous RMS vs. filtered RMS of Ay: (a) 0 SCTs and (b) 25 SCTs.

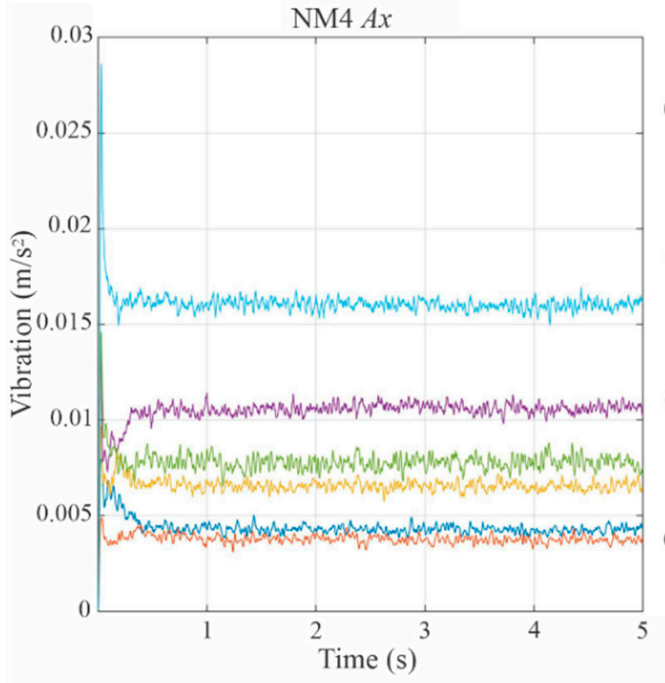

a)

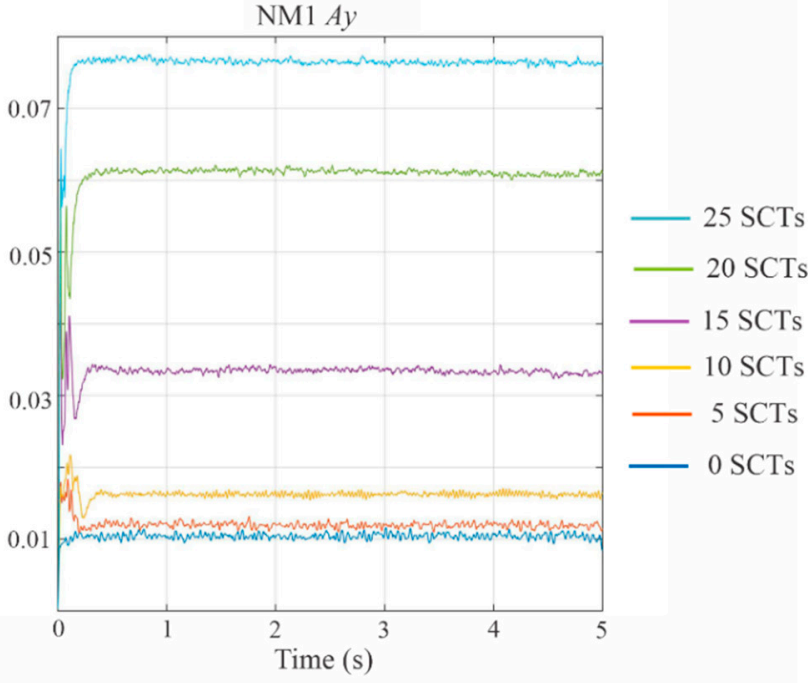

b)

Figure 8. RMS values for all conditions: (a) NM4 Ax and (b) NM1 Ay.

Finally, for automatic classification, an FL system is proposed. To obtain information about the input data, the mean and the standard deviation of the RMS values obtained for the 20 tests of each condition are computed. Table 1 presents the obtained results. With this information, the Gaussian distribution functions for the modes of interest (NM4 of $A x$ and NM1 of $A y$ in Table 1) can be plotted as shown in Figure 9. From these results, it is evident that the fuzzification process can be carried out through Gaussian membership functions. In this regard, a Mamdani-type fuzzy inference system is used. It has two inputs, 36 rules, and one output. Figure 8 shows the proposed membership functions for two inputs, NM1 $A y$ and NM4 $A x$, and one output, i.e., the transformer condition. The membership functions in Figure 10a are labeled as: very small value (VS), small value (S), normal value (N), high value $(\mathrm{H})$, very high values $(\mathrm{VH})$, very much high value $(\mathrm{VMH})$. On the other hand, the crisp output in Figure $10 \mathrm{~b}$ can have values ranging from 0.5 to 6.5 , where 0 SCTs $=1,5 \mathrm{SCTs}=2,10 \mathrm{SCTs}=3,15$ $\mathrm{SCTs}=4,20 \mathrm{SCTs}=5,25 \mathrm{SCTs}=6$. Table 2 shows the used rules in the inference mechanism, where each rule is read as follows if NM4 is N and NM1 is N then output is 10 SCTs. The inference mechanism performs minimum composition to quantify the output value and the defuzzification uses center of gravity [41]. 
Table 1. Mean $(\bar{x})$ and standard deviation $(\sigma)$ for the RMS values.

\begin{tabular}{|c|c|c|c|c|c|c|c|c|c|}
\hline & & \multicolumn{4}{|c|}{$A x$} & \multicolumn{4}{|c|}{$A y$} \\
\hline \multicolumn{2}{|c|}{ SCT } & NM1 & NM2 & NM3 & NM4 & NM1 & NM2 & NM3 & NM4 \\
\hline \multirow{2}{*}{0} & $\bar{x}$ & 0.0186 & 0.0125 & 0.0103 & 0.0037 & 0.0103 & 0.0059 & 0.0098 & 0.0024 \\
\hline & $\sigma$ & 0.0021 & 0.0012 & 0.000669 & 0.000544 & 0.000734 & 0.000711 & 0.0025 & 0.00028 \\
\hline \multirow{2}{*}{5} & $\bar{x}$ & 0.0124 & 0.012 & 0.0075 & 0.0044 & 0.0118 & 0.0115 & 0.0116 & 0.0057 \\
\hline & $\sigma$ & 0.0019 & 0.0021 & 0.000657 & 0.000411 & 0.000992 & 0.000914 & 0.0013 & 0.000652 \\
\hline \multirow{2}{*}{10} & $\bar{x}$ & 0.0194 & 0.0106 & 0.0092 & 0.0074 & 0.0167 & 0.0156 & 0.0102 & 0.0052 \\
\hline & $\sigma$ & 0.0016 & 0.0012 & 0.000789 & 0.000536 & 0.001 & 0.0014 & 0.000627 & 0.000537 \\
\hline \multirow{2}{*}{15} & $\bar{x}$ & 0.0215 & 0.0114 & 0.0113 & 0.0096 & 0.0376 & 0.0191 & 0.0104 & 0.0114 \\
\hline & $\sigma$ & 0.0024 & 0.000659 & 0.000934 & 0.000781 & 0.0023 & 0.001 & 0.000744 & 0.000971 \\
\hline \multirow{2}{*}{20} & $\bar{x}$ & 0.0151 & 0.0152 & 0.0116 & 0.0092 & 0.0611 & 0.0195 & 0.0104 & 0.0115 \\
\hline & $\sigma$ & 0.0021 & 0.0018 & 0.000997 & 0.000841 & 0.004 & 0.0011 & 0.000796 & 0.000709 \\
\hline \multirow{2}{*}{25} & $\bar{x}$ & 0.0219 & 0.0179 & 0.0097 & 0.0178 & 0.0753 & 0.0107 & 0.0165 & 0.0092 \\
\hline & $\sigma$ & 0.0019 & 0.0013 & 0.0011 & 0.0013 & 0.0044 & 0.000566 & 0.000888 & 0.000585 \\
\hline
\end{tabular}

a)

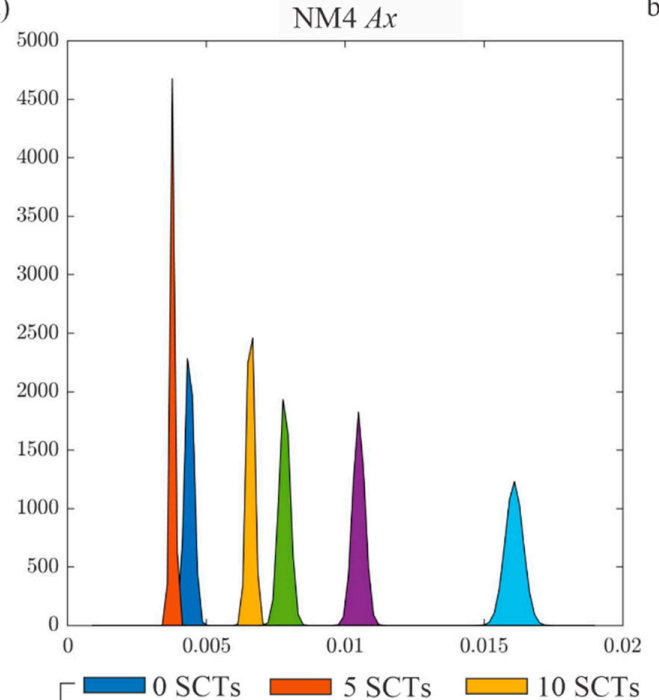

b)

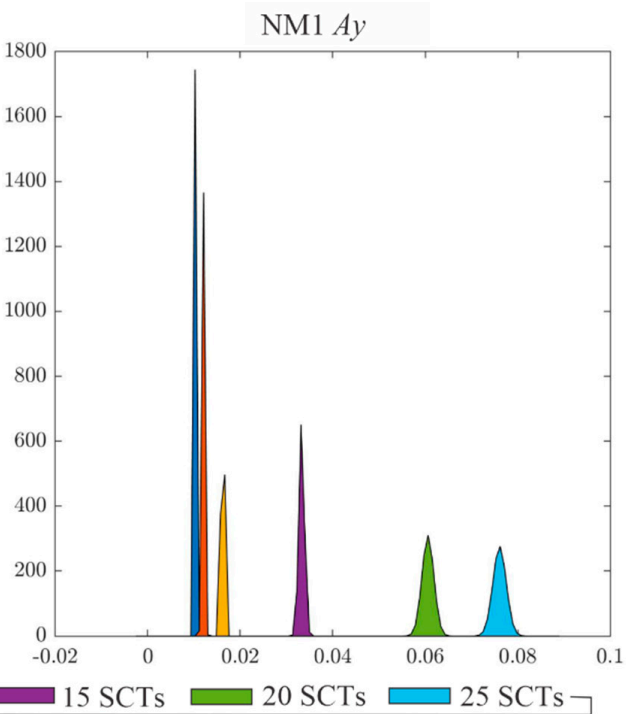

Figure 9. Density functions for (a) NM4 of $A x$ and (b) NM1 of $A y$.

a)
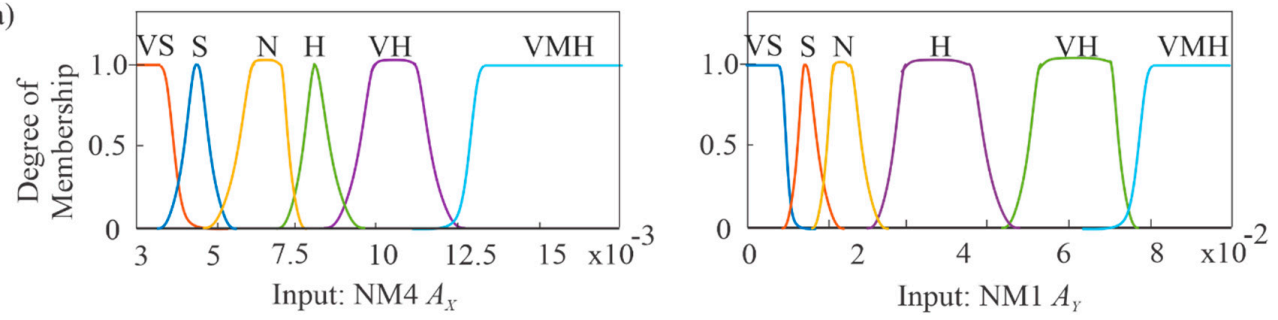

b)

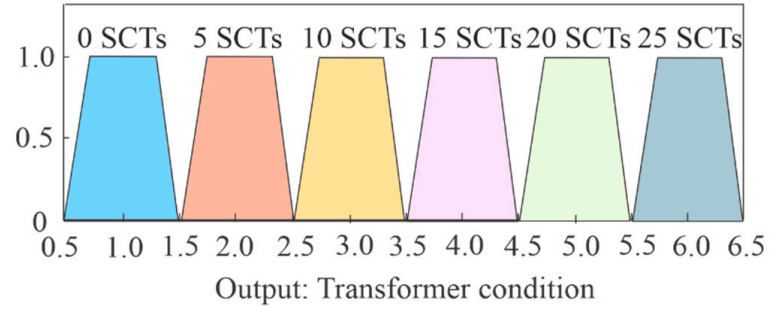

Figure 10. Membership functions for (a) inputs and (b) output. 
Table 2. Rules for the proposed fuzzy logic (FL) system.

\begin{tabular}{ccccccc}
\hline Inputs & \multicolumn{7}{c}{ NM1 } & & \\
\hline NM4 & VS & S & N & H & VH & VMH \\
VS & 0 & 5 & 10 & 15 & 20 & 25 \\
S & 0 & 5 & 10 & 15 & 20 & 25 \\
N & 0 & 5 & 10 & 15 & 20 & 25 \\
H & 0 & 10 & 10 & 15 & 20 & 25 \\
VH & 0 & 10 & 10 & 15 & 20 & 25 \\
VMH & 5 & 10 & 15 & 20 & 25 & 25 \\
\hline
\end{tabular}

All the numerical values are SCTs.

Finally, to test the overall methodology, 20 tests for each condition $(0,5,10,15,20,25$, and 30 SCTs) are assessed. Table 3 shows the obtained results as a confusion matrix. In the diagonal, the number of tests that have been correctly classified is presented. As can be observed, an effectiveness of $100 \%$ is obtained from 10 SCTs, which is expected since the higher the fault severity, the easier the way to detect it. Yet, for 5 SCTs, an effectiveness of $90 \%$ is obtained which is somehow good enough, mainly considering that a low fault severity can generate imperceptible vibration changes. It is important to mention that the most of the fault severities could be identified using the information provided by the NM1 Ay only, as shown the results in Figure 8b; yet, in the cases where the Gaussian functions are overlapped, other source of information is required to facilitate the decision-making process. In this case, the proposed FL system and the information provided by the two inputs allow addressing in a better way with the uncertainty generated by the overlap of classes.

Table 3. Confusion matrix.

\begin{tabular}{cccccccc}
\hline & 0 SCTs & 5 SCTs & 10 SCTs & 15 SCTs & 20 SCTs & 25 SCTs & Effectiveness (\%) \\
\hline 0 SCTs & 19 & 1 & 0 & 0 & 0 & 0 & 95 \\
5 SCTs & 1 & 18 & 1 & 0 & 0 & 0 & 90 \\
10 SCTs & 0 & 0 & 20 & 0 & 0 & 0 & 100 \\
15 SCTs & 0 & 0 & 0 & 20 & 0 & 0 & 100 \\
20 SCTs & 0 & 0 & 0 & 0 & 20 & 0 & 100 \\
25 SCTs & 0 & 0 & 0 & 0 & 0 & 20 & 100 \\
\hline
\end{tabular}

\subsection{Discussion}

Table 4 shows some relevant methodologies related to fault diagnosis of transformer windings. In particular, the proposal presents some advantages that have to be highlighted. For instance, the proposal identifies the winding short-circuit fault under different severity levels, unlike other approaches that only present the difference between a healthy transformer or a damaged transformer [11,21]. Also, the proposal can detect a fault considering transient and steady states, which is not addressed in other works $[11,17,21]$. On the other hand, unlike the works presented in $[17,21,22,26]$, the proposal offers an automatic diagnosis that is very important in order to avoid the need of expert users. Finally, the proposal can be considered as a low-complex solution since only three steps are required to (i) process the signal (NMD method), (ii) offer a fault indicator (HT-RMS), and (iii) automate the diagnosis (FLS) by considering different fault severities in transient and steady conditions. 
Table 4. Comparation of the proposed methodology against other relevant methodologies.

\begin{tabular}{|c|c|c|c|c|c|c|c|}
\hline Reference & Techniques & Analyzed State & Signal & $\begin{array}{c}\text { Sensors by } \\
\text { Winding or Phase }\end{array}$ & $\begin{array}{l}\text { Detected Fault in } \\
\text { Windings }\end{array}$ & $\begin{array}{l}\text { Types or Severity } \\
\text { Levels }\end{array}$ & $\begin{array}{c}\text { Automatic } \\
\text { Classification }\end{array}$ \\
\hline Proposal & NMD, HT-based RMS & Transient and steady & Vibrations & 1 & SCTs & 6 & FLS \\
\hline [11] & $\begin{array}{l}\text { Frequency complexity analysis, Vibration stationary } \\
\text { analysis, energy distribution analysis, and vibration } \\
\text { correlation analysis }\end{array}$ & Steady & Vibrations & 2 & $\begin{array}{l}\text { Aged transformer } \\
\text { and winding } \\
\text { deformations }\end{array}$ & 0 & $\begin{array}{l}\text { Support vector } \\
\text { machine }\end{array}$ \\
\hline [17] & Short time Fourier transform and RMS & Transient & Vibrations & 2 & Winding loosening & 4 & - \\
\hline [21] & $\begin{array}{l}\text { Wavelet packet transform, correlation degree threshold, } \\
\text { Hilbert Huang transform and energy }\end{array}$ & Steady & Vibrations & 2 & $\begin{array}{l}\text { Improvement in } \\
\text { the fault detection }\end{array}$ & 0 & - \\
\hline [22] & $\begin{array}{l}\text { Empirical wavelet transform, } \mathrm{HT} \text {, and collection of } \\
\text { sample entropies }\end{array}$ & Transient and steady & Vibrations & 2 & $\begin{array}{l}\text { Winding } \\
\text { deformation }\end{array}$ & 3 & - \\
\hline [26] & $\begin{array}{l}\text { Complete ensemble empirical mode decomposition, } \\
\text { Shannon entropy, RMS and energy index }\end{array}$ & Transient and steady & Current & 1 & SCTs & 6 & - \\
\hline
\end{tabular}

-no reported. 


\section{Conclusions}

Winding faults represent the most severe problem in a transformer; therefore, it is fundamental to develop methodologies that allow their detection on early stages and, thus, implement proper solutions. In this work, a new methodology for detection of SCTs in transformers from vibrations signals is proposed, where different fault severities, i.e., 0, 5, 10, 15, 20, and 25 SCTs, are studied. As a signal processing technique, the NMD method is investigated. Results demonstrate that this method can deal with the nonstationary and nonlinear properties of vibration signals generated during the transformer energization. In particular, the NM1 in y-axis and the NM4 in x-axis provide the most useful information to perform the fault detection. As fault indicator, the RMS index computed through the HT showed a proportional trend according to the fault severity. By combining the RMS values of the selected modes, the proposed FL system achieved an effectiveness superior to $90 \%$ in all the cases, including the 5 SCTs fault condition. Although promising results have been obtained, further research has to be carried out in larger transformers in order to increase the proposal applicability, even the fusion with other methods has to be considered with the aim of making more robust and reliable diagnosis systems. In fact, the potential of vibration signals to provide information that allows carrying out the fault detection makes necessary the application and research of other advanced signal processing techniques, e.g., the variational mode decomposition [43], the nonlinear chirp mode decomposition [44], and improvements in Gabor frames [45], among others.

In a future work, other types of fault such as loosening in core and windings, and other transformer operating conditions will be investigated, exploiting the inherent relationship between the transformer's mechanical properties and the vibration signals. Also, different fault indicators will be evaluated to determine their sensitive to the fault severity, exploiting the modes extracted by the NMD method and improving the fault detection capability, mainly in early stages.

Author Contributions: Conceptualization, J.R.H.-R. and M.V.-R.; investigation, resources, and visualization, J.R.H.-R., D.G.-L., and D.C.-M.; funding acquisition, J.P.A.-S. and M.V.-R.; Writing-original draft, review, and editing, all authors. All authors have read and agreed to the published version of the manuscript.

Funding: This research was funded by the "Consejo Nacional de Ciencia y Tecnología (CONACYT)" under the scholarship 734987.

Conflicts of Interest: The authors declare no conflicts of interest.

\section{References}

1. Hong, K.; Huang, H.; Zhou, J. Winding Condition Assessment of Power Transformers Based on Vibration Correlation. IEEE Trans. Power Deliv. 2015, 30, 1735-1742. [CrossRef]

2. Bagheri, M.; Naderi, M.; Blackburn, T. Advanced Transformer Winding Deformation Diagnosis: Moving from off-Line to on-Line. IEEE Trans. Dielectr. Electr. Insul. 2012, 19, 1860-1870. [CrossRef]

3. Valtierra-Rodriguez, M. Fractal dimension and data mining for detection of short-circuited turns in transformers from vibration signals. Meas. Sci. Technol. 2019, 31, 025902. [CrossRef]

4. Zheng, J.; Huang, H.; Pan, J. Detection of Winding Faults Based on a Characterization of the Nonlinear Dynamics of Transformers. IEEE Trans. Instrum. Meas. 2018, 68, 206-214. [CrossRef]

5. Zhang, Z.; Wu, Y.; Zhang, R.; Jiang, P.; Liu, G.; Ahmed, S.; Dong, Z. Novel Transformer Fault Identification Optimization Method Based on Mathematical Statistics. Mathematics 2019, 7, 288. [CrossRef]

6. Wang, M.; Vandermaar, A.J.; Srivastava, K.D. Review of Condition Assessment of Power Transformers in Service. IEEE Electr. Insul. Mag. 2002, 18, 12-25. [CrossRef]

7. Islam, M.M.; Lee, G.; Hettiwatte, S.N. A Review of Condition Monitoring Techniques and Diagnostic Tests for Lifetime Estimation of Power Transformers. Electr. Eng. 2018, 100, 581-605. [CrossRef]

8. Mejia-Barron, A.; Valtierra-Rodriguez, M.; Granados-Lieberman, D.; Olivares-Galvan, J.C.; Escarela-Perez, R. Experimental data-based transient-stationary current model for inter-turn fault diagnostics in a transformer. Electr. Power Syst. Res. 2017, 152, 306-315. [CrossRef]

9. Banaszak, S.; Kornatowski, E. Evaluation of FRA and VM measurements complementarity in the field conditions. IEEE Trans. Power Deliv. 2016, 31, 2123-2130. [CrossRef] 
10. Bartoletti, C.; Desiderio, M.; Di Carlo, D.; Fazio, G.; Muzi, F.; Sacerdoti, G.; Salvatori, F. Vibro-Acoustic Techniques to Diagnose Power Transformers. IEEE Trans. Power Deliv. 2004, 19, 221-229. [CrossRef]

11. Hong, K.; Huang, H.; Fu, Y.; Zhou, J. A Vibration Measurement System for Health Monitoring of Power Transformers. Meas. J. Int. Meas. Confed. 2016, 93, 135-147. [CrossRef]

12. Garcia, B.; Burgos, J.C.; Alonso, A.M. Transformer Tank Vibration Modeling as a Method of Detecting Winding Deformations-Part II: Experimental Verification. IEEE Trans. Power Deliv. 2006, 21, 164-169. [CrossRef]

13. García, B.; Burgos, J.C.; Alonso, Á.M. Transformer Tank Vibration Modeling as a Method of Detecting Winding Deformations-Part I: Theoretical Foundation. IEEE Trans. Power Deliv. 2006, 21, 157-163. [CrossRef]

14. Zhou, H.; Hong, K.; Huang, H.; Zhou, J. Transformer Winding Fault Detection by Vibration Analysis Methods. Appl. Acoust. 2016, 114, 136-146. [CrossRef]

15. Hu, C.; Wang, P.; Youn, B.D.; Lee, W.R.; Yoon, J.T. Copula-Based Statistical Health Grade System against Mechanical Faults of Power Transformers. IEEE Trans. Power Deliv. 2012, 27, 1809-1819. [CrossRef]

16. Hong, K.; Huang, H.; Zhou, J.; Shen, Y.; Li, Y. A Method of Real-Time Fault Diagnosis for Power Transformers Based on Vibration Analysis. Meas. Sci. Technol. 2015, 26, 115011. [CrossRef]

17. Borucki, S. Diagnosis of Technical Condition of Power Transformers Based on the Analysis of Vibroacoustic Signals Measured in Transient Operating Conditions. IEEE Trans. Power Deliv. 2012, 27, 670-676. [CrossRef]

18. Liu, Z.; Xia, X.; Ji, S.; Shi, Y.; Zhang, F.; Fu, Y.; Jiang, Z. Fault Diagnosis of OLTC Based on Time-Frequency Image Analysis of Vibration Signal. In Proceedings of the 2018 Condition Monitoring and Diagnosis (CMD), Perth, Australia, 23-26 September 2018.

19. Rivas, E.; Burgos, J.C.; García-Prada, J.C. Vibration Analysis Using Envelope Wavelet for Detecting Faults in the OLTC Tap Selector. IEEE Trans. Power Deliv. 2010, 25, 1629-1636. [CrossRef]

20. Kang, P.; Birtwhistle, D. Condition Assessment of Power Transformer On-Load Tap-Changers Using Wavelet Analysis. IEEE Trans. Power Deliv. 2001, 16, 394-400. [CrossRef]

21. Wu, S.; Huang, W.; Kong, F.; Wu, Q.; Zhou, F.; Zhang, R.; Wang, Z. Extracting Power Transformer Vibration Features by a Time-Scale-Frequency Analysis Method. J. Electromagn. Anal. Appl. 2010, 2, 31-38. [CrossRef]

22. Zhao, M.; Xu, G. Feature Extraction of Power Transformer Vibration Signals Based on Empirical Wavelet Transform and Multiscale Entropy. IET Sci. Meas. Technol. 2018, 12, 63-71. [CrossRef]

23. Shah, A.M.; Bhalja, B.R.; Member, S. Discrimination Between Internal Faults and Other Disturbances in Transformer Using the Support Vector Machine-Based Protection Scheme. IEEE Trans. Power Deliv. 2013, 28, 1508-1515. [CrossRef]

24. Valtierra-Rodriguez, M.; Amezquita-Sanchez, J.P.; Garcia-Perez, A.; Camarena-Martinez, D. Complete ensemble empirical mode decomposition on FPGA for condition monitoring of broken bars in induction motors. Mathematics 2019, 7, 783. [CrossRef]

25. Liu, X.; Yang, Y.; Huang, Y. Vibration Analysis of Transformer DC Bias Caused by HVDC Based on EMD Reconstruction. J. Electr. Eng. Technol. 2018, 13, 781-789.

26. Mejia-Barron, A.; Valtierra-Rodriguez, M.; Granados-Lieberman, D.; Olivares-Galvan, J.C.; Escarela-Perez, R. The Application of EMD-Based Methods for Diagnosis of Winding Faults in a Transformer Using Transient and Steady State Currents. Meas. J. Int. Meas. Confed. 2018, 117, 371-379. [CrossRef]

27. Duan, R.; Wang, F. Fault Diagnosis of On-Load Tap-Changer in Converter Transformer Based on Time-Frequency Vibration Analysis. IEEE Trans. Ind. Electron. 2016, 63, 3815-3823. [CrossRef]

28. Geng, C.; Wang, F.; Zhang, J.; Jin, Z. Modal Parameters Identification of Power Transformer Winding Based on Improved Empirical Mode Decomposition Method. Electr. Power Syst. Res. 2014, 108, 331-339. [CrossRef]

29. Camarena-Martinez, D.; Valtierra-Rodriguez, M.; Perez-Ramirez, C.A.; Amezquita-Sanchez, J.P.; de Jesus Romero-Troncoso, R.; Garcia-Perez, A. Novel Downsampling Empirical Mode Decomposition Approach for Power Quality Analysis. IEEE Trans. Ind. Electron. 2016, 63, 2369-2378. [CrossRef]

30. Saxena, M.K.; Raju, S.D.V.S.J.; Arya, R.; Pachori, R.B.; Ravindranath, S.V.G.; Kher, S.; Oak, S.M. Empirical Mode Decomposition-Based Detection of Bend-Induced Error and Its Correction in a Raman Optical Fiber Distributed Temperature Sensor. IEEE Sens. J. 2016, 16, 1243-1252. [CrossRef]

31. Amarnath, M.; Krishna, I.R.P. Detection and Diagnosis of Surface Wear Failure in a Spur Geared System Using EEMD Based Vibration Signalanalysis. Tribol. Int. 2013, 61, 224-234. [CrossRef] 
32. Valles-Novo, R.; de Jesus Rangel-Magdaleno, J.; Ramirez-Cortes, J.M.; Peregrina-Barreto, H.; Morales-Caporal, R. Empirical Mode Decomposition Analysis for Broken-Bar Detection on Squirrel Cage Induction Motors. IEEE Trans. Instrum. Meas. 2015, 64, 1118-1128. [CrossRef]

33. Iatsenko, D.; McClintock, P.V.E.; Stefanovska, A. Nonlinear Mode Decomposition: A Noise-Robust, Adaptive Decomposition Method. Phys. Rev. E 2015, 92, 032916. [CrossRef] [PubMed]

34. García, B.; Burgos, J.C.; Alonso, Á. Winding Deformations Detection in Power Transformers by Tank Vibrations Monitoring. Electr. Power Syst. Res. 2005, 74, 129-138. [CrossRef]

35. Iatsenko, D.; McClintock, P.V.E.; Stefanovska, A. Linear and Synchrosqueezed Time-Frequency Representations Revisited: Overview, Standards of Use, Resolution, Reconstruction, Concentration, and Algorithms. Digit. Signal Process. 2015, 42, 1-26. [CrossRef]

36. Iatsenko, D.; McClintock, P.V.E.; Stefanovska, A. Extraction of Instantaneous Frequencies from Ridges in Time-Frequency Representations of Signals. Signal Process. 2016, 125, 290-303. [CrossRef]

37. Iatsenko, D.; McClintock, P.V.; Stefanovska, A. Linear and synchrosqueezed time-frequency representations revisited. Part ii: Resolution, reconstruction and concentration. arXiv 2013, arXiv:1310.7274.

38. Wang, X.; Deck-Leger, Z.-L.; Zou, L.; Azana, J.; Caloz, C. Microwave Hilbert Transformer and Its Applications in Real-Time Analog Processing. IEEE Trans. Microw. Theory Tech. 2019, 67, 2216-2226. [CrossRef]

39. Urbina-Salas, I.; Razo-Hernandez, J.R.; Granados-Lieberman, D.; Valtierra-Rodriguez, M.; Torres-Fernandez, J.E. Instantaneous power quality indices based on single-sideband modulation and wavelet packet-Hilbert transform. IEEE Trans. Instrum. Meas. 2017, 66, 1021-1031. [CrossRef]

40. Golestan, S.; Ramezani, M.; Guerrero, J.M.; Freijedo, F.D.; Monfared, M. Moving Average Filter Based Phase-Locked Loops: Performance Analysis and Design Guidelines. IEEE Trans. Power Electron. 2014, 29, 2750-2763. [CrossRef]

41. Kuncheva, L. Fuzzy Classifier Design; Springer Science \& Business Media: Berlin, Germany, 2000; Volume 49.

42. Valtierra-Rodriguez, M.; Granados-Lieberman, D.; Torres-Fernandez, J.E.; Rodríguez-Rodríguez, J.R.; Gómez-Aguilar, J.F. A new methodology for tracking and instantaneous characterization of voltage variations. IEEE Trans. Instrum. Meas. 2016, 65, 1596-1604. [CrossRef]

43. Dragomiretskiy, K.; Zosso, D. Variational Mode Decomposition. IEEE Trans. Signal Process. 2014, 62, 531-544. [CrossRef]

44. Chen, S.; Dong, X.; Peng, Z.; Zhang, W.; Meng, G. Nonlinear Chirp Mode Decomposition: A Variational Method. IEEE Trans. Signal Process. 2017, 65, 6024-6037. [CrossRef]

45. De Carli, L.; Vellucci, P. Stability results for Gabor frames and the p-order hold models. Linear Algebra Appl. 2018, 536, 186-200. [CrossRef]

(C) 2020 by the authors. Licensee MDPI, Basel, Switzerland. This article is an open access article distributed under the terms and conditions of the Creative Commons Attribution (CC BY) license (http://creativecommons.org/licenses/by/4.0/). 